\title{
TO THE READERS
}

GMJ. 2013;2(3):87

www.gmj.ir

\section{Galen Medical Journal is One Year Old}

Surfing on the wings of time, days turned into weeks, weeks turned into months, and, I found myself at a point to write you for the first time at the first anniversary of publishing of Galen Medical Journal (GMJ). First of all, on behalf of the Editorial Board of GMJ, I want to thank all the subscribers, supporters, and readers of GMJ for giving hand for improvement of the journal and introducing it globally. GMJ began its activities as a scientific research journal in medical sciences by a small group of young medical researchers with a great goal which was to have a reliable highly cited international journal for publishing genuine studies and outcomes from researchers in medical sciences all over the world. This team made serious efforts from the beginning to increase its international profile by inviting internationally renowned academics to the Editorial Board. We developed a user-friendly Web site and followed international standards, such as the policies and guidelines from the World Association of Medical Editors (WAME), to ensure the quality of this journal. We are also pleased to inform you that we have provided a fast review process and making decision on any manuscript we receive in less than 4-6 weeks.

GMJ is now well-known by robots of various Web search engines including Google and Yahoo. It is now indexed by Directory of
Open Access Journals (DOAJ), Islamic World Science Citation (ISC), Regional Information Center for Science and Technology (RICEST), Index Copernicus, Scientific Information Database(SID), IranMEDEX, Magiran, Google Scholar, Electronic Journals library, and Geneva Free Medical Journals. Currently GMJ web-site receives an average of 500 hits a day and the number of visitors is steadily increasing since its launch in 2012.

The Editorial Board of GMJ gives their special regards to Dr. Farrokh Habibzadeh, President of WAME for his valuable advices for improving the quality of GMJ. Also, the Editorial Board wants to thank Dr. Soheil Ashkani-Esfahani, who made a significant improvement in the quality of papers and management of the publishing process of GMJ after being added to the board as the Deputy and Copy editor.

None of these achievements and improvements could have been reached without the support of our readers, authors, reviewers and Board members. Thank you all for your kind attention and cooperation and I hope you will continue to support us in order to reach what you expect us to.

\author{
Aliasghar Karimi MD, \\ Editor, Galen Medical Journal
}

\section{GMJ}

o2013 Galen Medical Journal

Fax: +98 7312227091

PO Box 7461686688

Email:info@gmj.ir 